\title{
Workers and Head of Departments: Investigating the Trust Factor
}

\author{
Chua Bee Seok, Aminuddin I. Lastar, Tan Cho Chiew, Jasmine Adela Mutang, Lailawati Madlan, and \\ Alfred Chan Huan Zhi
}

\begin{abstract}
This study aims to provide further information on the topic of Malaysian workers trust towards their head of departments. A total of 185 workers $($ males $=81$, females $=104$ ) from four of the Malaysia's government department in Kota Kinabalu, Sabah were selected as the respondents in this study. The respondents completed an open-ended questionnaire regarding what are the underlying reasons that the employees trust their head of department and how much they trust their head of departments. The results from the thematic analysis revealed that there are five main themes have been identified from the generated data for workers' basis of trust development towards their head of department. Namely, 1) status privileges and role; 2) competency; 3) benevolence; 4) worker - leader relationship, and 5) head of department's integrity. From the above identified themes, it was found that, status privileges and roles along with the head of department's competency are among the two most important aspects in the development of trust in workers towards their head of department.
\end{abstract}

Index Terms-Trust, status privileges, competency, benevolence, integrity and worker-leader relationship.

\section{INTRODUCTION}

Golembiewski and McConkie [1] state that "there is no single variable which so thoroughly influences interpersonal and group behavior as does trust." Cook and Wall [2] concluded that "trust between individual and groups are a highly important ingredient in the long-term stability of the organization and the well-being of its members." These two statements highlighted that trust is a critical element in constructive human relationships and it is an important element for organizations to develop and maintain. Trust that individuals have in their employer and organization will motivate them to put in more effort and more commitment in their task, whereas those who do not trust their employer and organization may reduce the effectiveness of their work [3], [4], their job performance, citizenship to the organization, job satisfaction, organizational commitment and increase intent to quit [5], [6].

Rousseau, Sitkin, Burt, and Camerer [6] claimed that the definition of trust has been much debated in the literature. This may due to trust is conceptualized differently across different research agendas and across culture. In the study of

Manuscript received August 28, 2013; revised November 19, 2013. This work was supported in part by the Ministry of Higher Education, Malaysia under Grant ERGS00007-SS-1/2011.

B. S. Chua, I. L. Aminuddin, M. Jasmine, and M. Lailawati are with School of Psychology and Social Work, Universiti Malaysia Sabah, Malaysia (e-mail: chuabs@ums.edu.my, lastar_ai@yahoo.co.uk).

C. C. Tan is now with ITE Kent Campus, Tuaran, Sabah, Malaysia (e-mail: chochiew@yahoo.com.my). propensity to trust, Mayer et al. [5] defined trust as an individual difference construct. In the study of organization engenders trust and the trust development in organization by Bradach and Eccles [7] and Chua et al. [8], trust was defined as a feature of institutions. While it lies in the relationship between individuals [9], [10] trust was defined as a feature of interactions.

In cultural perspective, Hofstede [11] had been suggested two cultural dimensions (i.e., power distance and individualism-collectivism) that can apply to the employee's trust in the supervisor. Power distance refers to the extent to which a society can accepts status privileges and tolerates with power differences [12]. Employee trust in the supervisor may vary depending on the kind of power distance relationship that the culture endorses. While, in-group collectivism (another cultural dimension), refers to the extent to which persons have pride and loyalty in their families, close friends, and in the organization where they work [13].

Like many Asian countries, Malaysia is considered to be high power distance and high in-group collectivist countries. Hence, to understand the concept of trust in this collectivist community it is essential to investigate how trust is developed in the employees toward their head of department in Malaysia. In doing so, rather than assuming a normative view of how trust is developed in Western countries (individualist cultures) and using that as the basis for inferring trust development in Malaysia (collectivist cultures). In addition, Kim, Yang, and Hwang [14] claimed that "When a psychologist looks at a non-western culture through western glasses, he may fail to notice important aspects of the non-western culture since the schemata for recognizing...." Thus, in this current study we applied an indigenous psychology approach that ask the respondents to articulate the content regarding what are the underlying reasons that they trust their head of department and the range of variables they consider are relevant to describe the concept of trust. The indigenous psychologies approach emphasizes contextualized understanding rooted in a particular setting (e.g. cultural context, political, historical, or ecological). It emphasizes the discovery and use of natural taxonomies in search of regularities, general principles, and universal laws [15].

\section{METHOD}

\section{A. Participants}

A total of 185 workers $($ males $=81$, females $=104)$ from four of the Malaysia's government department in Kota Kinabalu, Sabah were selected as the respondents in this 
study. There were 81 male employees $(33.8 \%)$ and 104 female employees (64.4\%). Their ages ranged from 20 to 58 years old with the min of 41.67 years old. Their average tenure with their current employer was 11.2 years $($ s.d. $=7.5$ years).

\section{B. Measure}

The study was based on a set of open-ended question to elicit information on adolescents' trust toward their mother. The questionnaire was designed by the researches to measure the degree and the underlying reason why the workers trust their head of department and organization. The questionnaire comprised two parts: A demographic information section and a section of trust measure. The demographic variables included gender, age, race, religion, marital status, and tenure with the current company. The trust measure comprised of six questions that measure the degree and the reason why the workers trust and not trust their head of department, co-workers, and their company.

\section{Statistical Analysis}

The data was analyzed in the steps listed by Braun and Clarke [16] for thematic analysis, which involved finding repeated patterns of meaning within the data. Analysis data begin with data transcription, familiarization with the data by multiple readings and an initial noting of ideas. Next, the initial coding was conducted across the data and these codes were then collected into potential themes. The themes were then reviewed to certain that they were appropriate both at the level of individual extracts and across the data set.

\section{RESULTS AND DISCUSSION}

\section{A. Workers' Basis of Trust Development towards Their Head of Department}

There are five main themes have been identified from the generated theme analysis results for workers' basis of trust development towards their head of department. Namely, 1) status privileges and role; 2) competency; 3) benevolence; 4) worker - leader relationship, and 5) head of department's integrity. From the above identified themes, it was found that, status privileges and roles along with the head of department's competency are among the two most important aspects in the development of trust in workers towards their head of department.

Status privileges and role refers to, the trust in the head of department is given because of the nature of the status privileges itself and also due to the rules and regulations. Other than that, the development of that trust is also because of the role and responsibilities which the head of department have to carry. This is according to responses provided by 52 people or $23.50 \%$ respondents. The analysis summary of respondents' frequency of responses for each identified components is shown in Table I.

The second most important aspect in the basis of trust development in workers towards their head of department is due to the head of department's competency. There were 51 people or $23.10 \%$ respondents out of 185 public and private sectors workers have provided this respond. Competency aspect, according to this research is refers to the leader's capability in providing guidance or assistance to his/her subordinates; leader's self-competency; leader's work performance; and also the leadership quality depicts by him/her.

TABLE I: MAIN COMPONENTS AND SUB-COMPONENTS IN WORKERS' BASIS OF TRUST DEVELOPMENT TOWARDS THEIR HEAD OF DEPARTMENT

\begin{tabular}{|c|c|c|c|c|c|}
\hline $\begin{array}{l}\text { Main } \\
\text { Component }\end{array}$ & $\mathrm{n}$ & $\%$ & $\begin{array}{l}\text { Sub- } \\
\text { Component }\end{array}$ & $\mathrm{n}$ & $\%$ \\
\hline \multirow[t]{3}{*}{ Job and role } & 52 & 37.30 & $\begin{array}{l}\text { Status } \\
\text { privileges }\end{array}$ & 26 & $\begin{array}{c}14.6 \\
9\end{array}$ \\
\hline & & & $\begin{array}{l}\text { Role as head } \\
\text { of department }\end{array}$ & 19 & $\begin{array}{c}10.7 \\
3\end{array}$ \\
\hline & & & $\begin{array}{l}\text { Rules / } \\
\text { regulations }\end{array}$ & 7 & 3.95 \\
\hline \multirow[t]{2}{*}{$\begin{array}{l}\text { Relationshi } \\
\mathrm{p}\end{array}$} & 36 & 19.00 & $\begin{array}{l}\text { Relationship } \\
\text { in } \\
\text { collaboration }\end{array}$ & 19 & \\
\hline & & & $\begin{array}{l}\text { Respect } \\
\text { toward head of } \\
\text { department }\end{array}$ & 17 & 9.60 \\
\hline \multirow[t]{4}{*}{$\begin{array}{l}\text { Competenc } \\
\text { y }\end{array}$} & 51 & 27.60 & $\begin{array}{l}\text { Assisting / } \\
\text { guiding }\end{array}$ & 21 & $\begin{array}{c}11.2 \\
6\end{array}$ \\
\hline & & & Competency & 14 & 7.91 \\
\hline & & & $\begin{array}{l}\text { Work } \\
\text { performance }\end{array}$ & 9 & 5.08 \\
\hline & & & $\begin{array}{l}\text { Leadership } \\
\text { characteristics }\end{array}$ & 7 & 3.95 \\
\hline \multirow{2}{*}{$\begin{array}{l}\text { Benevolenc } \\
\mathrm{e}\end{array}$} & 31 & 16.80 & Concern / care & 16 & 9.04 \\
\hline & & & Responsibility & 15 & 8.47 \\
\hline \multirow[t]{5}{*}{ Integrity } & 34 & 18.40 & $\begin{array}{l}\text { signs of } \\
\text { integrity }\end{array}$ & 6 & 3.39 \\
\hline & & & Fair & 7 & 3.95 \\
\hline & & & Confidence & 5 & 2.82 \\
\hline & & & $\begin{array}{l}\text { Personality / } \\
\text { positive / kind } \\
\text { / honest }\end{array}$ & 9 & 5.08 \\
\hline & & & Behaviors & 7 & 3.95 \\
\hline Total & $\begin{array}{c}18 \\
5\end{array}$ & $\begin{array}{c}100.0 \\
0\end{array}$ & & & \\
\hline
\end{tabular}

Relationship between workers and leader is identified as the third most important elements in the development of trust among workers towards their head of department. This response was provided by 36 people or $16.30 \%$ of the respondents both from the public and private sectors. From the mentioned response, the basis of their trust towards the head of department is due to their interactions in collaboration with the head of department; have been working together in collaboration for a long period of time; know their leader's personality; and the sense of respect towards the leader.

Integrity is found as the fourth important aspect in the basis of workers' trust development towards their head of department. This was according to 34 people or $15.4 \%$ of the respondents answer in this research. The head of department's integrity is judged based the signs of his/her integrity; unbiased conduct in his/her management; personality; positive attitudes and mannerism; kindness and honesty; and feel confidence towards the head of department.

The final basis of trust development towards head of department which has been identified was based on the workers' feeling towards their head of department as a person who is concern about the workers' welfare; is care about the workers' essential and responsible on their well-being. 
Therefore, this trust component is labeled as benevolence. There were 31 workers or $14.00 \%$ respondents have provided this statement.

In the detail analysis on sub-components of workers' development of trust towards their head of department, it was found that, the majority of the respondents stated that, they trust their head of department because of the status of that job. There were many of the workers who have indicated that, they trust their head of department is solely due to the person is their leader or a higher-ranking person. It was also found among them who said that, it is an obligatory to trust a leader, and it should not be any problem at all to trust a head of department because they take work instructions from the head of department. There were also opinions which indicated that the head of department is always right. The employee's statements in this matter about the head of department is as follows: "boss"; "obligation"; "because he/she is my superior"; "have to trust because they are the bosses"; "employer"; "as the leader" and "the boss is always right”.

Assisting and guiding element is the second important sub-component which has been reported by the workers as the reason of their trust towards the head of department. Employee respondents in this research responded that they trust their head of department because he/she assists and guides, and also encourages the workers towards betterment and success. It was also said that, head of department offers advices and guidance so that the workers could improve their work performance; head of department is also a person who the workers seek for advise and share their problems. These following statements made by the respondents on this matter are describe as: "guiding and leading the department workers to success"; "helping a lot"; "always gives me orders which enable me to improve my service that has made me became and achieved an excellent service personnel"; and "giving plenty of directions and always offering advices".

Both of these sub-components, role as a head of department and relationship in collaboration have been identified as the third most important trust component towards the head of department. From the responses provided by the respondents, it was found that, if a head of department seeks trust from his/her subordinates, the head of department should be someone who knows what actually is going around in the office, he/she also should be capable to direct the department towards the organization success, capable of giving instructions and make decision, and also has capability to materialize the organization's visions. Statements from the workers regarding this aspect about their head of departments are as follows: "because he/she is the head of department who gives instructions"; "department decision maker"; "so it is called head of department, surely understand the situation and know how"; and "head of department materializes the organization's visions".

Workers' trust development towards head of department which is based on relationship in collaboration is refers to, collaboration and good relationship between workers and head of department; understanding between the two parties; and both parties have experience and been working together for a long time. The workers' response on this aspect are as follows: "good collaboration"; "there is an understanding with the leader"; because of the relationship between an employee and the leader in completing the task"; "have been working together for 16 years and already know his/her personality"; and "been years under the supervision".

Furthermore, respect towards head of department also reported as an important basis in the development of workers' trust towards their head of department. There were workers who reported that, they trust their head of department because of their sense of respect towards leader and because the person is a leader so they should respect him/her. Among the responses indicated that a leader needs to be respected are: "feeling respect"; "respectful leader"; "need to respect"; "should respect"; and "respecting as a leader".

The next workers' basis of trust development towards their head of department is head of department's concern and compassionate towards his/her subordinates. Workers have trust in their head of department because they feel that their welfare and essential are well looking in to by a responsible head of department. Responses provided by the respondents representing these two aspects are as follows: "concern about the workers' welfare”; "concern about workers' needs"; "he/she concerns about his/her subordinates"; "never put aside workers' welfare"; "considerate and responsible"; "believing on the basis of the responsibilities that he/she have to carry"; "responsible towards the subordinates' welfare"; and "he/she is responsible for me".

Head of department's competency in managing is also one of the workers' bases of trust development towards their head of department. This competency is refers as a leader's capability in managing a department, decision making, projecting unfailing ideas, and capable in delegating tasks. Workers' statements on their head of department's competency as an aspect of their trust development basis are as the following: "believe that he/she could manage the department"; "because capable to manage the department perfectly"; "giving unfailing ideas, quick in decision making"; "delegates tasks perfectly"; and "every decisions gets necessary consideration".

Besides that, workers in this research have also stated that they trust their head of department because they know about work performance, leadership characteristics, personality and positive attitudes, kindness, honesty, integrity, fairness and have confidence in their head of department. There were also workers among others have indicated that, they have trust in their head of department because they believe there are guidelines and regulations which have to follow by a head of department. Respondents' statements regarding these components are: "they do their jobs well"; "his/her credibility as a leader has been proven, I know him/her as an honest person"; managing the organization/ department fairly and just"; "high integrity, discipline"; "good personality and portraying good examples to workers"; "confidence and capable"; "positive attitudes"; "confident that all policies made are for workers' benefits"; all decisions are based on regulations"; and "because they are intellectuals and obey all rules".

In comparison to the findings from the Western countries, it was found that the results from this research are relevant to 
Organization Trustworthiness Model suggested by Mayer and colleagues [5]. Although Mayer and colleagues view trustworthiness and trust are two different properties, hence, three of the organization trustworthiness outlined by them, namely competency, benevolence, and integrity are consistent with the trust concept reported by the respondents in this research. According to Mayer, et al. [5], those three features are the basis or reasons for workers to have trust in their head of department.

Besides those three components, there are two additional aspects have been identified in this research which have also contribute to the workers' basis of trust development in their head of department. These two components are status privilege and role as a head of department, and relationship between workers and head of department. These findings could probably be explained by the differences in culture practiced by certain society. To the Westerners (individualistic culture), a head of department can be trusted if the person possesses capability, able to look after the workers' welfare, and has to be a person with integrity. Contrary, Asians who are taught from a younger age to respect a much older person and a leader, have reported that, status privilege and head of department's role as an important component in the basis of their trust development towards head of department (collectivist culture). The finding was consistent with Hofstede's [11] taxonomy (i.e., power distance and individualism-collectivism) which that suggested in applying to the employee's trust of the supervisor. He claimed that employee trust in the supervisor may vary depending on the kind of power distance relationship which refer to the culture endorses status privileges and a society tolerates to the power differences and to to which persons have pride and loyalty in their families, close friends, and in the organization in which they work [13].

Additionally, in Asian society, a relationship with others is also an important part in the basis of trust development between two parties. For example, in Korean culture, the concept of relationship is termed as Jung (attachment); in Chinese culture, it is known as Guanxi (relationship); while in Japanese is Amae (refinements); whereas the concepts of Asih, Asah, and Asuh (compassion, develop, and foster) are found in Indonesian culture [17]. Even though, the term used for relationship across Asia is dissimilar from one to another, but they are all in constancy with the concept of trustworthiness. The finding also Consistent with the survey by Wong et al. [18], interpersonal relationship between supervisor and subordinate was directly related to subordinates' trust in their supervisors. Yong, Peng and Zhu [19] also claimed that supervisor-subordinate guanxi (relationship) is a reliable predictor for trust in supervisor in Chinese firms with different types of ownership.

\section{CONCLUSION}

From this research, it was found that status privileges and leader's role; competency; benevolence; relationship between workers and leader; and leader's integrity are identified as the five most important basis in trust development among workers towards their head of department. Sub-components detail analysis has generated that, the most important basis of workers' trust development towards their head of department is the job held by a person, follows by other components as per assisting and guiding; role; relationship with the leader; sense of respect to a leader; leader's concern and compassionate; leader's competency and so forth. From these findings, it is shown that this research has successfully explored the concept of trust in organization on local culture setting and its society's opinions. These findings have also clearly shown that there is an existence of differences in conceptual definitions between the Western world and local society. Overall, the findings from this research has successfully contributed in generating a better understanding of trust concept centered on local setting, enriching academic references, and its contribution to the local organizations in fostering a better understanding of their workers' behaviors which could influence the development and progress of the organization.

The strength of this study lies in the use of rich qualitative data and indigenous psychology approach which emphasizes contextualized understanding rooted in a particular setting (e.g. cultural context, political, historical, or ecological), and the discovery and use of natural taxonomies in search of regularities, general principles, and universal laws [20]. Nonetheless, our results should be evaluated in view of possible recall biases inherent to such research designs and the sample selected to be representative of different types of organization and sectors cannot be fully generalized.

\section{REFERENCES}

[1] R. T. Golembiewski and M. McConkie, "The centrality of interpersonal trust in group processes," in C. L. Cooper (Ed.), Theories of Group Processes, New York: Wiley, 1975, pp. 131-185.

[2] J. Cook and T. Wall, "New work attitude measures of trust, organizational commitment and personal need non-fulfillment," Journal of Occupational Psychology, vol. 53, pp. 39-52, 1980.

[3] K. T. Dirks and D. L. Ferrin, "The role of trust in organizational settings," Organization Science, vol. 12, pp. 450-467, 2001.

[4] K. T. Dirks and D. L. Ferrin, "Trust in leadership: Meta analytic findings and implications for research and practice," Journal of Applied Psychology, vol. 87, pp. 611-628, 2002.

[5] R. Mayer, J. H. Davis, and E. D. Schoorman, "An integrative model of organizational trust," Academy of Management Review, vol. 20, no. 3, pp. 709-734, 1995.

[6] D. M. Rousseau, S. B. Sitkin, R. S. Burt, and E. Camerer, "Not so different after all: A cross-discipline view of trust," Academy of Management Review, vol. 23, pp. 393-404, 1998.

[7] J. L. Bradach and R. G. Eccles, "Price, authority, and trust: From ideal types to plural forms," Annual Review of Sociology, vol. 15, pp. 97-118, 1989.

[8] B. S. Chua and C. C. Tan, "Trust, trustworthiness and justice perception toward the head of department," Global Journal of Arts Humanities and Social Sciences, no. 1, pp. 20-29, 2013.

[9] R. J. Lewicki and B. B. Bunker, "Developing and maintaining trust in work relationships," in R. M. Kramer and T. R. Tyler (Eds.), Trust in Organizations: Frontiers of Theory and Research, Thousand Oaks, CA: Sage, pp. 114-139, 1996.

[10] F. D. Schoorman, R. C. Mayer, and J. H. Davis, "An integrative model of organizational trust: Past, present, and future," Academy of Management Review, vol. 32, pp. 344-354, 2007.

[11] G. Hofstede, Culture's Consequences: International Differences in Work Related Values, Beverly Hills, CA: Sage. 1980.

[12] D. Carl, V. Gupta, and M. Javidan, "Power distance," in R. J. House, P. J. Hanges, M. Javidan, P. W. Dorfman and V. Gupta (Eds.), Culture, Leadership, and Organizations, Thousand Oaks, CA: Sage, 2004, pp. 513-563.

[13] D. Robert, R. D. Costigan, R. C. Insinga, J. J. Berman, and S. S. Ilter, "The effect of employee trust of the supervisor on enterprising behavior: A cross-cultural Comparison," Journal of Business and Psychology, vol. 21, no. 2, pp. 273-291, 2006. 
[14] U. Kim, K. S. Yang, and K. K. Hwang, "Contributions to indigenous and cultural psychology," Indigenous and Cultural Psychology: Understanding People in Context, pp. 3-25, 2006.

[15] U. Kim and J. W. Berry, Psychologies: Experience and Research in Cultural Context, Newbury Park, CA: Sage. 1993.

[16] V. Braun and V. Clarke, "Using thematic analysis in psychology," Qualitative Research in Psychology, vol. 3, no. 2, pp. 77-101, 2006.

[17] J. A. Mutang, C. H. Z. Alfred, N. Ayub, B. S. Chua, Ismail, R. Ooh Siew Ling, and U. Kim, "Why I trust my father? In the eyes of Malaysian adolescents," World Academy of Science, Engineering and Technology, vol. 72, pp. 740-74, 2012.

[18] Y. T Wong, H. Ngo, and J. M. Wong, "Antecedents and outcomes of employees' trust in Chinese joint ventures," Asia Pacific Journal of Management, vol. 20, pp. 481-499. 2003.

[19] Y. Han, Z. Peng, and Y. Zhu, "Supervisor-subordinate Guanxi and trust in supervisor: A qualitative inquiry in the people's Republic of China," Journal of Business Ethics, vol. 108, pp. 313-324, 2012.
[20] U. Kim, Culture, "Science and indigenous psychologies: An integrated analysis," in D. Matsumoto (Ed.), Handbook of culture and psychology Oxford, Oxford University Press, 2001, pp. 51-76.

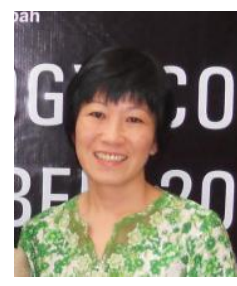

Chua Bee Seok is a Ph.D. She is a head of Psychology and Social Health Research Unit in Universiti Malaysia Sabah. She is also an associate professor in School of Psychology and Social Work. She is specializing in Industrial and Organizational Psychology and had more than 15 years experiences in teaching Psychological Testing and Measurement, and Personnel Testing course in School of Psychology and Social Work. She involved in more than 20 research projects. Her primary research interests are work stress, organizational behavior, and psychological testing and measurement. Her current projects include "Stereotype, Prejudice and Discrimination among Multi Ethnic in Sabah, Malaysia"; "Developing and Psychometric Properties of Happiness Scale"; and "Exploring the concept of Trust in Malaysian society". 